DOI: 10.14526/2070-4798-2019-14-4-40-47

\title{
Non-doping psychological-pedagogical, medical-biological methods of rehabilitation and working capacity improvement in athletes-combatants
}

\author{
GizatullinR.Z. ${ }^{1}$, MutaevaI.Sh ${ }^{2 *}$, MutaevA.M. ${ }^{3}$ \\ ${ }^{1}$ Chaikovskiy State Institute of Physical Culture \\ Chaikovskiy, Russia \\ ORCID: oooo-ooo1-6632-7274, Grz1983@mail.ru \\ ${ }^{2}$ Yelabuga Institute (branch) of Kazan (Volga) Federal University \\ Elabuga, Russia \\ ORCID: oooo-0oo2-9387-7033, mutaeva-i@mail.ru* \\ 3University of Management "TISBI" \\ Naberezhnye Chelny, Russia \\ ORCID: oooo-Ooo2-9042-4354, mutaevam61@mail.ru
}

\begin{abstract}
The article considers peculiarities of using non-doping means of physical working capacity rehabilitation in athletes-combatants. It is mentioned that in terms of considerable intensity increase of the training and competitive loads, the questions concerning effective working capacity preservation and increase become more urgent, including the questions of rehabilitation events use in macro cycle of sports training. Materials and methods.The methods of specialists' works analysis and summarizing are used in the sphere of physical culture and sport. A questionnaire survey was held among respondents, concerning the questions of psychological-pedagogical, medical-biological methods of rehabilitation use during the training process of students, who go in for wrestling in terms of sports school, after the training and competitive loads. Results. After summarizing the works of specialists we revealed that nondoping means of rehabilitation use for working capacity improvement in athletes-combatants becomes urgent at all stages of sports training. We revealed the degree of awareness in athletescombatants concerning the questions of rehabilitation means use. From psychological means of rehabilitation emotional relieving, auto-training, meditation and motivations were mentioned. Medical-biological means of rehabilitation are widely used during sports training after the training and after competitions. Popular means of rehabilitation turned out to be sauna. Conclusion. The presented scheme of rehabilitation events organization and realization, based on taking into account currant and integral functional state of wrestlers, helps to provide an adequate and rational use of rehabilitation means, their individualization and high effectiveness.
\end{abstract}

Keywords: athletes-combatants, means of rehabilitation, survey, scheme.

For citation: Gizatullin R.Z., Mutaeva I.Sh., Mutaev A.M. Non-doping psychological-pedagogical, medical-biological methods of rehabilitation and working capacity improvement among athletescombatants. Russian Journal of Physical Education and Sport. 2019; 14(4): 34-40. DOI: 10.14526/20704798-2019-14-4-40-47

\section{INTRODUCTION}

Wrestling development is connected with its popularization increase among young people. Nowadays wrestling has different kinds, it develops owing to rules of competitions and methods of sports training change. Combats demand considerable power abilities, quickness, endurance, coordination, dexterity and flexibility. During wrestling there is power abilities demonstration, within a short time period quickness, coordinating abilities are realized. Combats have a great influence on neuromuscular system, locomotor apparatus and a functional state of athletes.

Sports training in the groups of sportsmanship improvement demands not only regular trainings, but also different rehabilitation measures.

Scientific-methodical sources and special literature analysis showed that many research workers are interested in different sides of training athletes.

In the works of many authors it is mentioned that rehabilitation measures are the main component of training athletes in different kinds of sport $[1,2,3]$.

Ch. A. Gizzatulina (2012) considers the effective way of physical working capacity and results improvement among sprinters, taking into account their type of blood circulation [4].

A.I. Zhuzhgov (2014) underlines the 
importance of military-applied physical training as the base for a high level of cadets' physical health, which can be the main indicator of the main educational process individualization and health improvement [5].

E.A. Zolotova (2013) underlines that taking into account the indices of heart activity among female athletes is the main part of control over the level of physical loads realization of different orientation [6].

A.V. Kokovkin (2014) wrote about the necessity to use rehabilitation means in sports training of wrestlers. He proved that rehabilitation measures should be complex and should have local and general effect $[7,8]$.

A.V. Kochnev (2011) considered the use of hardware-controlled means of rehabilitation in sports training of female synchronized swimmers. The author underlines that planning rehabilitation means in micro- and meso- and macro cycles of training, taking into account functional indices, provides general and special physical working capacity increase. The author mentions that rehabilitation means should be held every day in terms of medical control and self-control over the state of the organism. The effectiveness of hardwarecontrolled rehabilitation means use was proved experimentally $[9,10,11]$.

M.O. Mirzoev (2005) reveals theoretical aspects and general principles of different rehabilitation means use in the training process of athletes in different kinds of sport. He underlines a complex character of rehabilitation means realization in macro cycle of training [12].

I.V. Nyunyaev (2015) studies reserve functional and adaptive capacities taking into consideration among athletes for endurance development using the ways of rehabilitation and working capacity improvement. The base of his concept is the fact that physical working capacity depends on endurance development. Rehabilitation processes of the organism are activated in terms of adequate means realization in aerobic regimen as the base of heart activity effectiveness increase as the index of adaptation to physical loads. Rehabilitation processes in this terms are effective [13,14].
M.V. Nikityuk (2014) considers bio-energetic basis of physical working capacity improvement in athletes. The author proves the necessity to take into consideration bio-energetic profile of athletes for physical working capacity and effectiveness of rehabilitation processes improvement after physical loads of different orientation [15].

R.A. Solnitsyn (2011), studying the peculiarities of training cadets, underlines the necessity to fulfill motor actions in terms of tiredness, which leads to working capacity increase [16].

All mentioned above proves the urgency of the innovative methodologies creation problem, rehabilitation measures realization in sports training of wrestlers as the condition for antidote sports training.

The importance of non-doping rehabilitation means improvement among athletes is the base in the tiredness solution problem.

The aim of this research work was awareness determination in athletes-combatants concerning psychological-pedagogical, medical-biological means of rehabilitation use after maximum and training loads.

\section{MATERIALS AND RESEARCH METHODS}

We used the methods of works analysis and summarizing written by the specialists in the sphere of physical culture and sport. We carried out the questionnaire survey in athletes-combatants (18-21 years old), who go in for sportsmanship development groups. According to the results of the survey we revealed the degree of awareness in athletes concerning psychological-pedagogical, medical-biological means of rehabilitation and their use for rehabilitation and physical working capacity increase after the training and competitive loads.

\section{RESULTS AND DISCUSSION}

Medical-biological means, used in training athletes-combatants, are different. It can be noted that hardware-controlled and manual massage, thermic (bath houseand sauna) and water procedures (swimming pool, aqua-aerobics, shower), lymphatic drainage are widely used. Nowadays acupuncture and manual therapy are also very popular. A wide 
variety of rehabilitation procedures helps to avoid monotony. However their uncontrolled use can make harm. That is why the question of an adequate and purposeful use of rehabilitation means is still urgent. Many specialists and athletes mention that not controlled use of different rehabilitation means can lead to undesired consequences, such as muscular activity decrease, muscles relaxation, noncoordination of movements. For example, the use of bath procedures before the competitions can lead to adaptive abilities of an organism decrease with physical working capacity decrease.

A questionnaire survey among wrestlers of different qualification helped to reveal the degree of their awareness concerning the questions of rehabilitation means of psychological-pedagogical and medical-biological orientation.

Table 1 -Results of a questionnaire survey among athletes concerning the questions of rehabilitation means use of psychological-pedagogical, medical-biological orientation

\begin{tabular}{|c|c|c|}
\hline The means of working capacity rehabilitation & $\begin{array}{l}\text { Percentage of } \\
\text { athletes' awareness } \\
(\mathrm{n}=34)\end{array}$ & $\begin{array}{l}\text { Percentage of use } \\
(\mathrm{n}=34)\end{array}$ \\
\hline \multicolumn{3}{|l|}{ Pedagogical means } \\
\hline Rational planning & 8 & 3 \\
\hline $\begin{array}{c}\text { Training loads correspondence with the training level of } \\
\text { athletes }\end{array}$ & 10 & 5 \\
\hline Rational micro-, -meso, and macro cycles organization & 11 & 5 \\
\hline Rehabilitation means inclusion into the process of training & 10 & 35 \\
\hline \multicolumn{3}{|l|}{ Psychological means } \\
\hline Means of emotional relieving & 5 & 5 \\
\hline Auto-training, meditation & 35 & 15 \\
\hline Motivation & 25 & 30 \\
\hline \multicolumn{3}{|c|}{ Medical-biological means } \\
\hline Rational nutrition & 45 & 23 \\
\hline Physio-and water procedures & 20 & 15 \\
\hline Massage,including hardware-controlled one & 46 & 34 \\
\hline Lymphatic drainage & 2 & 1 \\
\hline Bath house, sauna & 100 & 100 \\
\hline Pharmacology (vitamins andsports drinks) & 57 & 43 \\
\hline
\end{tabular}

The use of non-doping means of working capacity rehabilitation in sports training is connected with the volume and intensity of the training and competitive loadsincrease.

Table 1 shows that the percentage of awareness in athletes concerning pedagogical means of rehabilitation corresponds with a low level, only $39 \%$ of respondents have the notion of pedagogical means of rehabilitation. They knew about it from their coaches. $48 \%$ of respondents use pedagogical means of rehabilitation and mentioned their orientation toward the effectiveness of competitive activity increase.

From psychological means of rehabilitation the respondents underlined the use of emotional relieving, auto-training, meditation, self-analysis, self-regulation, motivation level increase. At the same time, $100 \%$ of respondents preferred autotraining.

$65 \%$ of respondents know about psychological means of rehabilitation. 50\% of respondents have practice of their use.

Medical-biological means of rehabilitation are widely used by athletes during sports training after the training and after competitions. The most popular turned out to be sauna as the means of rehabilitation and weight reduction. 100\% of respondents showed awareness in sauna using as 
the key and available rehabilitation means. 46\% of respondents mentioned massage use. $45 \%$ of respondents underlined that a rational nutrition can also be an effective rehabilitation means. At the same time, the respondents underlined, that a rational nutrition was the means, which demands considerable financial expenditure. Most part of respondents has budgetary nutrition. Athletes' awareness concerning pharmacological means and vitamins, used for energetic balance rehabilitation, was $57 \%$.

The percentage of medical-biological rehabilitation means use differs from the percentage of awareness. We underline a low level of rational nutrition, physio-procedures and lymphatic drainage use.

Thus, the results of the survey helped to reveal, that the respondents' awareness level concerning rehabilitation means was at the average level.

The received results prove the necessity to increase the importance of the presented means of rehabilitation for physical working capacity preservation and improvement in athletes.

Tactics of rehabilitation means use should be created by the coach together with the athlete, taking into account his needs, desires and recommendations. Unit weight of each rehabilitation means is defined depending on how an athlete can bare the increasing loads. For example, the training process intensification in athletes-combatants can lead to adaptation disruption. In this connection, there appears the necessity to restore not only physical indices, but also psychic state of an athlete. In order to decrease psychic tension it is necessary to use auto-training, attention redirection, psychotraining and other techniques.

Rehabilitation means choice and the unit weight of the means is conditioned by the state of an athlete.

Sports combats are characterized by maximum physical loads fulfillment in combats and competitions in general. In this connection it is necessary to think about rehabilitation means among wrestlers in the macro cycle of training.

Maximum physical loads are realized by the athletes during basic micro cycles and during competitive period of training. For quick rehabilitation of physical working capacity medicalbiological means of rehabilitation are used. Psychological state of wrestlers during competitions is regulated owing to psycho-regulating means, taking into consideration individual psychological peculiarities of athletes.

The works analysis and our observations showed that for a successful rehabilitation events realization it is necessary to create structure of rehabilitation measures planning, organization and realization in the macro cycle of training, taking into account the orientation of the training lessons.

Picture 1 presents the scheme of rehabilitation measures realization in wrestlers of sportsmanship improvement groups.

Scheme of rehabilitation means organization and realization for working capacity increase in the macrocycle of training athletes-combatants includes wrestlers' training level monitoring in current, operative and integral aspects and also physical, functional and psychological state estimation. On this basis we choose and realize rehabilitation means at three stages of training wrestlers. In further research works we will present the content of rehabilitation means realization and working capacity increase in the macrocycle of training among athletes-combatants.

This structure of rehabilitation measures realization in the macrocycle of training will help to increase the importance of non-doping rehabilitation measures and means.

\section{Conclusion}

The presented scheme of rehabilitation means (based on taking into account current and integral functional state of wrestlers) realization and organization for physical working capacity rehabilitation helps to provide an adequate and rational use of rehabilitation means, their individualization and high effectiveness. This scheme can be urgent for athletes of different specialization and stages of training. For the experimental effectiveness substantiation of non-doping means of rehabilitation use it is necessary to estimate and control functional state of athletes, which will provide rehabilitation means individualization. 


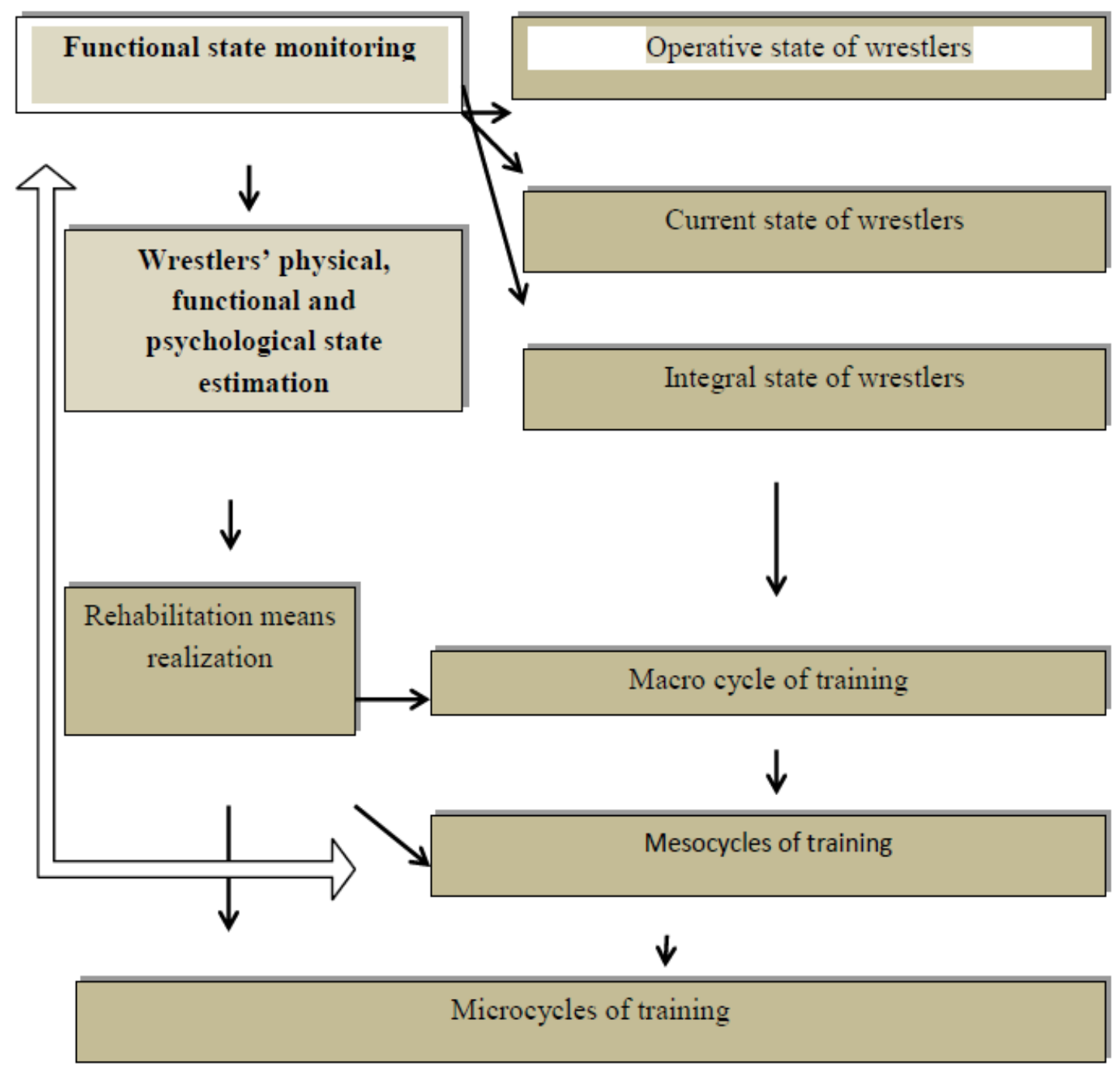

\section{Estimation and result}

Picture 1-Scheme of rehabilitation means organization and realization for working capacity increase in the macrocycle of training athletes-combatants

\section{REFERENCES}

1. Houlihan B. Dying to win: Doping in sport and the development of anti-doping policy. Strastburg: Council of Europe Publishing. 2002.

2. Mottram D.R. Prevalence of drug use in sport. Drugs in sport. 2005: 357-380.

3. Stray-Gundersen J., Videman T., Pentilla I., Lereim I. Abnormal hematologic profiles in elite cross-country skiers: Blood doping or? Clinical Journal of Sport Medicine. 2003; 13: 132-137.

4. Todd J., Todd T. Significant events in the history of drug testing and the Olympic movement: 1960-1999. Doping in elite sport: The politics of drugs in the Olympic movements. 2001; 65-128.

5. Avanesov V. U. Problems and the ways of special working capacity increase in sprint. Teoriya I praktika fizicheskoj kul'tury is sporta $=$ Theory and practice of physical culture. 2007; 12: 38-41. (In Russ., In Engl.) 
6. Gizatullina Ch.A., Mutaeva I.Sh. Ways of training individualization among sprinters on the basis of taking into account typological peculiarities of blood circulation. Pedagogiko-psyhologicheskie I mediko-biologicheskie problemy fizicheskoj cultury i sporta. 2012; 3(24): 11-119. URL: http:// journalsport.ru/images/vipuski/7-1/3.pdf Russ.)

7. Zhuzhgov A.I. Level of physical load at military-applied physical training lessons among cadets of higher educational establishments. Materialy Vserossijskoj nauchno-prakticheskoj konferencii $s$ mezhdunarodnym uchastiem "Strategichekie napravleniya reformirovaniya vuzovskoj sistemy fizicheskoj kul'tury" [Materials of All-Russian scientific-practical conference with International participation "Strategic orientations of University system of physical culture reformation", December, 3-4, 2014]. Saint-Petersburg, 2014: 134140. (In Russ.)

8. Zolotova E.A. Physical loads influence on heart rate of 8-13 year-old girls, who go in for synchronized swimming. Sportivnoe nasledie Universiady - 2013: materialy Vserossijskoj nauchno-prakticheskoj konferencii [Sports heritage of Universiade -2013: materials of All-Russian scientific-practical conference]. Naberezhnye Chelny.2010: 251-252. (In Russ.)

Kokovkin A.V., Ryabuk A.V. Experimental methodology substantiation of complex use of rehabilitation means in a yearly cycle of training highly-qualified Greco-Roman wrestlers. Pedagogiko-psihologicheskie I medicobiologicheskie problemy fizicheskoj kul'tury I sporta = Pedagogico-psychological and medico-biological problems of physical culture and sport. 2014; 3(32): 47-53. URL: http://journalsport.ru/index. $\mathrm{php} / \mathrm{ru} /$ arkhiv-nomerov/9-uncategorised/567tom-9-4-2014 (In Russ., In Engl.)

Kokovkin A.V., Ryabchuk A.V. Contraction and relaxation indices of muscles among GrecoRoman style wrestlers during the complex of rehabilitation measures use at the stage of sports improvement. Fizicheskaya kul'tury, sport - nauka I praktika. 2014; 1: 36-42 (In Russ.).

Kochnev A.V. Indices of general and special physical training of highly- qualified female synchronized swimmers depending on rehabilitation means. Pedagogikopsihologicheskie I medico-biologicheskie problemy fizicheskoj kul'tury I sporta = Pedagogicopsychological and medico-biological problems of physical culture and sport. 2011; 4(21): 91-102 URL: http://journalsport.ru/images/vipuski/6-1/4. pdf (In Russ., In Engl.)

Kochnev A.V., Kuznetsov A.S. Hardwarecontrolled rehabilitation means influence on functional readiness indices among female synchronized swimmers. Uchenye zapiski universiteta imeni P.F. Lesgafta. 2011; 11: 18-21 (In Russ.)

Kochnev A.V. Hardware-controlled rehabilitation means use during precompetitive meso-cycle of training female synchronized swimmers. Fizicheskaya kul'tury, sport - nauka I praktika. Krasnodar. 2011; 4: 28-33.

9. Mirzoev O.M. Rehabilitation means use in sport. Moscow: SportAcademPress. 2000: 203.

Nyunyaev I.V. The indices of functional and adaptive reserves of students' organism during physical upbringing lessons. Pedagogicalpsychological and medical-biological problems of physical culture and sport. 2015; 1(34): 37-41. URL: http://kamgifk.ru/magazin/journal.htm.

Nyunyaev I.V., Gibadullin I.G. The indices of physical and psychological reserves of students' organism. Pedagogiko-psihologicheskie I medicobiologicheskie problemy fizicheskoj kul'tury I sporta = Pedagogico-psychological and medicobiological problems of physical culture and sport. 2015; 1(34): 37-41. URL: http://journalsport.ru/ index.php/ru/arkhiv-nomerov?id=383 (In Russ., In Engl.)

10. Nikityuk M.V. Bio-energetic basis of muscle activity effectiveness improvement in different kinds of sport. Podgotovka edinobortsev: teoriya, metodika I praktika: sbornik materialov IV Vserossijskoj nauchno-prakticheskoj konferencii [Training combatants: theory, methodology and practice: collection of materials of the IV All-Russian scientific-practical conference]. Chaikovskiy Institute of Physical Culture. Chaikovskiy: from and to. 2014: 105-109 (In Russ.). 
11. Solonitsyn R.A. Directed development of moor abilities of cadets at higher educational establishments of Federal Service of Punishment Execution in Russia for accurate shooting in terms of tiredness. Sbornik nauchnyh trudov molodyh uchenyh [Collection of scientific works of young scientists]. Chaikovskiy: Chaikovskiy State Institute of Physical Culture. 2011: 50-53.

12. Haugen K.K. The performance enhancing drug game. Journal of Sport Economics. 2004; 5: 67-86.

Velonews. Ricco admits to doping. Velonews. 2008. URL: http://tour-defrance.velonews.com/ article/81064/.

WADA. The world Anti-Doping Code: International Standard for Laborotories, Version 4.0. 2004b. URL: http://www.wada-ama.org/ rtcontent/document/lab_aug_04.pdf.

Wagner G.G. The triple doping dilemma - an economic analysis of anti-doping regulations. Die Aktualitat der Sportphilosophie (The relevance of the philosophy of sport). 1993: 143-158.

Yesalis C.E., Bahrke M.S. Doping among adolescent athletes. Bailliries Clinical Endocrinology and Metabolism. 2000; 14: 25-35.

\section{Submitted: 20.10.2019}

\section{Author's information:}

Gizatullin R.Z. - Postgraduate, Chaikovskiy State Institute of Physical Culture, 617764, Russia, Chaikovskiy, Lenin str., House 67, e-mail:Grz1983@mail.ru

Mutaeva I.Sh. - Candidate of Biological Sciences, Professor, Elabuga Institute (branch) of Kazan (Volga) Federal University, 4236oo, Russia, Elabuga, Kazanskaya str., House 89, e-mail: mutaeva-i@ mail.ru

Mutaev A.M. - Senior Lecturer, University of Management "TISBI", 42381o, Russia, Tatarstan str., House10, e-mail:mutaevam61@mail.ru 